\title{
Bio-Prospecting Procedure of Sky-Hold Banana (Musa troglodytarum L.): Protection of the Rights of Indigenous Community in Maluku Islands, Indonesia
}

\author{
Semuel Leunufna* \\ Faculty of Agriculture Pattimura University, Center for the Conservation of Maluku's Biodiversity (CCMB), Ambon, Indonesia \\ *Corresponding author: Semuel Leunufna, Faculty of Agriculture Pattimura University, Center for the Conservation of \\ Maluku's Biodiversity (CCMB), Ambon, Indonesia
}

\section{ARTICLE INFO}

Received: 慧 February 25, 2020

Published: 絊 March 04, 2020

Citation: Semuel Leunufna. Bio-Prospecting Procedure of Sky-Hold Banana (Musa troglodytarum L.): Protection of the Rights of Indigenous Community in Maluku Islands, Indonesia. Biomed J Sci \& Tech Res 26(2)2020. BJSTR. MS.ID.004327.

Keywords: Bioprospecting; Sky-Hold Banana; Maluku Islands; Material Transfer Agreement; Indigenous Community

\begin{abstract}
This study described the protocol implemented in bio-prospecting activities related to samples preparation and transfer of sky-hold banana (Musa troglodytarum L.) from Maluku islands Indonesia to the Netherlands, through collaboration among Faculty of Agriculture Pattimura University, PT Olop, Hila Kaytetu, Ambon Island, and Agrofair Company Barrendrecht, the Netherlands. The handling and transporting of biological materials including field and laboratory preparation, packaging, quarantine inspection, shipping and receiving of the materials were successfully completed. However, a number of constrains were identified and suggested to be improved. The protection of rights of indigenous community was ensured through the signing of a Material Transfer Agreement (MTA). This report/study has been the first attempt to propose the bioprospecting protocol in Maluku Province, Indonesia.
\end{abstract}

Abbreviations: MTA: Material Transfer Agreement; SMTA: Standard Material Transfer Agreement; ITC: International Transit Center; CBD: Convention of Biological Diversity

\section{Introduction}

Bioprospecting is a systematic and organized search for useful products derived from bio-resources including plants, animals, microorganisms, that can be developed further for commercialization and overall benefits of the society [1]. Bioprospecting activities are continuing to increase in the word. However, the escalation in samples collection activities, mainly by big companies in developed countries, is not correspond to the establishment and improvement of regulations especially in the countries, which have sovereignty over the biodiversity components, and as a consequence, benefit sharing, agreed upon in the Convention of Biological Diversity (CBD), Rio de Janeiro, 1992, is mainly not implemented, ignoring the rights of the indigenous communities. One of the limitations in bio-prospecting is, there are no effective guidelines and conditions defined for recognizing and rewarding the contribution of indigenous people and other informal innovators who are responsible for nurturing, using and developing biodiversity [2]. Indeed, ASEAN workshop on the TRIPS agreement and traditional Medicine held in Jakarta, 2001 emphasized the importance of developing mechanism to ensure that knowledge and resources are not used without full, informed consent of their holders and finding ways to ensure equitable sharing of the benefits [3].

The richness of Maluku islands in banana genetic diversity is well documented [4-7]. This gene pool is a foundation where specific genotypes can be pooled out to be further developed in the area of agronomy, pharmaceutical food industry and others. Study to evaluate the potential of selected genotypes would be a first step to further development in the industries indicated above. The idea of bioprospecting on sky-hold banana is initiated by Agrofair Company, the Netherlands following a research visit to Ambon island by its 
Managing Director accompanying two scientists from Bio-based research, Wageningen University and Research, the Netherlands. Recently, sky hold banana has received more research attention $[8,9]$ due mainly to its presumably high content of $\beta$-carotene, and its role in traditional means of treating certain diseases. The species has also been covered as one of the target crops, on which research and lectures are focused, in a joint project between Indonesia and the Netherlands named "Setting up a blended learning program for sustainable inclusive agricultural value chain development in Indonesia". This study reports a technical procedure implemented in the above bio-prospecting activity in Maluku islands Indonesia. It also attempts to discuss the protection of the rights of indigenous community on biodiversity, in addition to indicating aspects to be improved for further development.

\section{Materials and Methods}

\section{Materials}

The main plant materials used were sky-hold or fehi banana (Musa troglodytarum L.) of long finger obtained from 3 different locations in Ambon Island (Figure 1). Machete was used to cut down the banana tree and to separate the hands from the bunch. The short finger sky-old banana obtained from the market was also part of the materials, which was obtained from the traditional market since it was relatively less cultivated in comparison to the one with long finger. Equipment such as blender made of glass, papers, tapes, cartoon, etc., for puree preparation and packaging as well as researchers involved were presented in Figures $2 \mathrm{a} \& 2 \mathrm{~b}$. Autoclave and laminar flow hood were main laboratory equipment used.
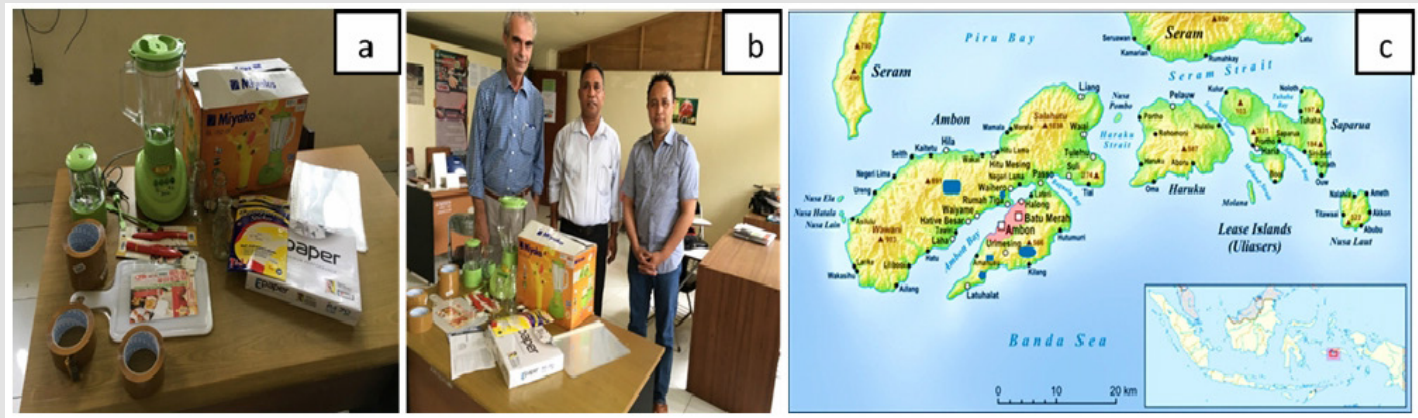

Figure 1:

(a) Some of the tools used in puree preparation and product packaging.

(b) Three researchers involved in the material preparation: Mr. Frits Blessing, senior consultant at PT Ollop, the Netherlands, Dr. Semuel Leunufna of the Faculty of Agriculture Pattimura University and Mr. Fahmi Ollong of PT Ollop, Hila Kaitetu, Ambon Island.

(c) Map of Ambon island indicating areas where the materials were obtained; The blue rounded rectangle represent Taeno Atas sub-village, blue rectangle represent Siwang sub-village and blue elliptical circle represent Naku village (Source: Lencer CC BY-SA 3.0).
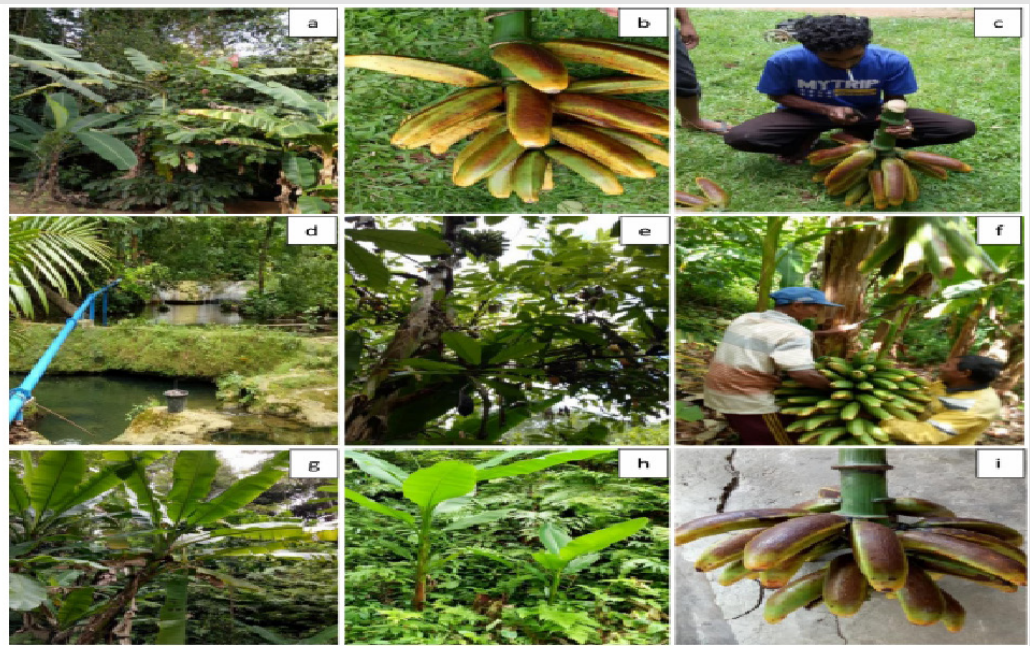

Figure 2: Surrounding areas at the places where the sky-hold banana (Musa troglodytarum L) were harvested). (a - c) Siwang sub-village,

(d - f) Taeno Atas sub-village,

(g - i) Naku village.

Harvested three days before puree preparation. 


\section{Methods}

To find out about the present and the maturity stage of skyhold banana tree, a number of field surveys were conducted to different villages and sub-villages including Seri, Siwang, Naku, Kilang, Hatalai, Soya, Waringin cap, Air ali, and Taeno atas. Three villages and sub-villages at three different parts (environmental condition) of Ambon Island were identified as having the sky-hold banana plants, which were at the similar developmental stages. At the appointed time and more or less the right maturity stage of banana (fully developed fruit exhibiting yellow-red color), the tree was cut down carefully avoiding any bumping, crushing, wound or cut on the fruit. Prior to puree preparation at tissue culture laboratory of the Faculty of Agriculture, Pattimura University, the equipment such as blender, bottles, knife etc. were sterilized in an autoclave. Some parts of the equipment which were not possible to be sterilized using autoclave were cleaned thoroughly using $70 \%$ alcohol under the laminar flow hood. Following the setting up of the equipment under the laminar flow hood, banana finger were cut into several pieces and stirred in the blender to become puree.

The puree was then poured into the bottles available. Following the puree preparation, the bottles containing puree were placed in an autoclave at $90{ }^{\circ} \mathrm{C}$ for 10 minutes as a way of pasteurizing the materials. Quarantine official's investigation on bio-prospecting materials was accomplished at the quarantine office of Ambon Municipality. Previously, an appointment was made the day before and an official form requesting the inspection of materials to be sent has been filed out. In addition to a number of bottles contain sky-hold banana puree; the package was also filled with samples of banana powder in a small plastic bag and two hands of needle banana (Musa acuminata L.). Several ways of sending the package to the request institution in the Netherlands was attempted. The package, however, finally was sent to the Netherlands by means of aero plane personal cabin carry due to some disadvantages encountered in the other shipping providers. The concept of Material Transfer Agreement was prepared by the provider institution, Faculty of Agriculture Pattimura University and signed by all parties involved, the provider institution, the received institution, and the researcher from both parties.

\section{Results}

\section{Handling Procedure of the Bio-Prospecting Materials}

Field Activities: General growing conditions of sky-hold banana are higher altitude, high humidity, and high vegetation coverage, sloped, mostly in dusun system (traditional multiple cropping system practiced in Maluku Islands) but also in a mixed cropping system. Similarity in maturity stage of the samples from different locations could not be obtained despite efforts made to determine accordingly. The felling of plant and cutting out of hands and fingers are conducted according to the protocol (no crushing, no bruise or wound etc.) (Figure 2). Three days after cutting, the fingers become ripen showing red in color and soft skin, ready for puree production (Figure 3).
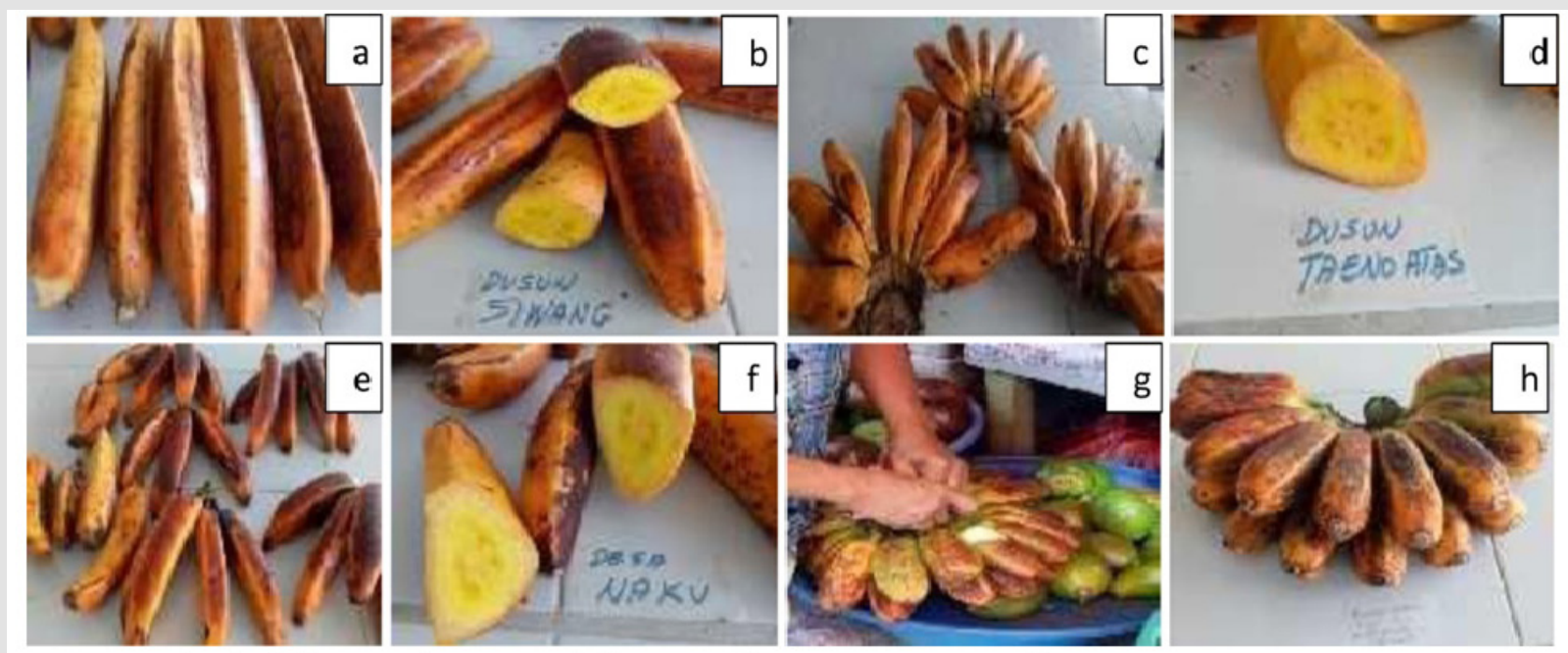

Figure 3: Sky-hold banana (Musa troglodytarum L.) ripening stage at the time proir to puree preparation.

$(\mathbf{a}, \mathbf{b})$ Long finger cultivar Banana from Siwang sub-village,

(c, d) From Taeno Atas sub-village,

(e, f \& h) From Naku village.

$(\mathrm{g}, \mathrm{h})$ Short finger cultivar from the Mardika market.

Laboratory Activities: The puree is successfully produced and poured into the bottles prepared. Samples from one harvest area, however, exhibits an uneven ripening fruit (uneven fruit's consistency), which mightreduce the quality of puree.Pasteurization in 900C for $10 \mathrm{~min}$. is considered necessary to ensure prevention of contamination during transportation, in addition to sterilization of working environment and equipment used (Figure 4). 

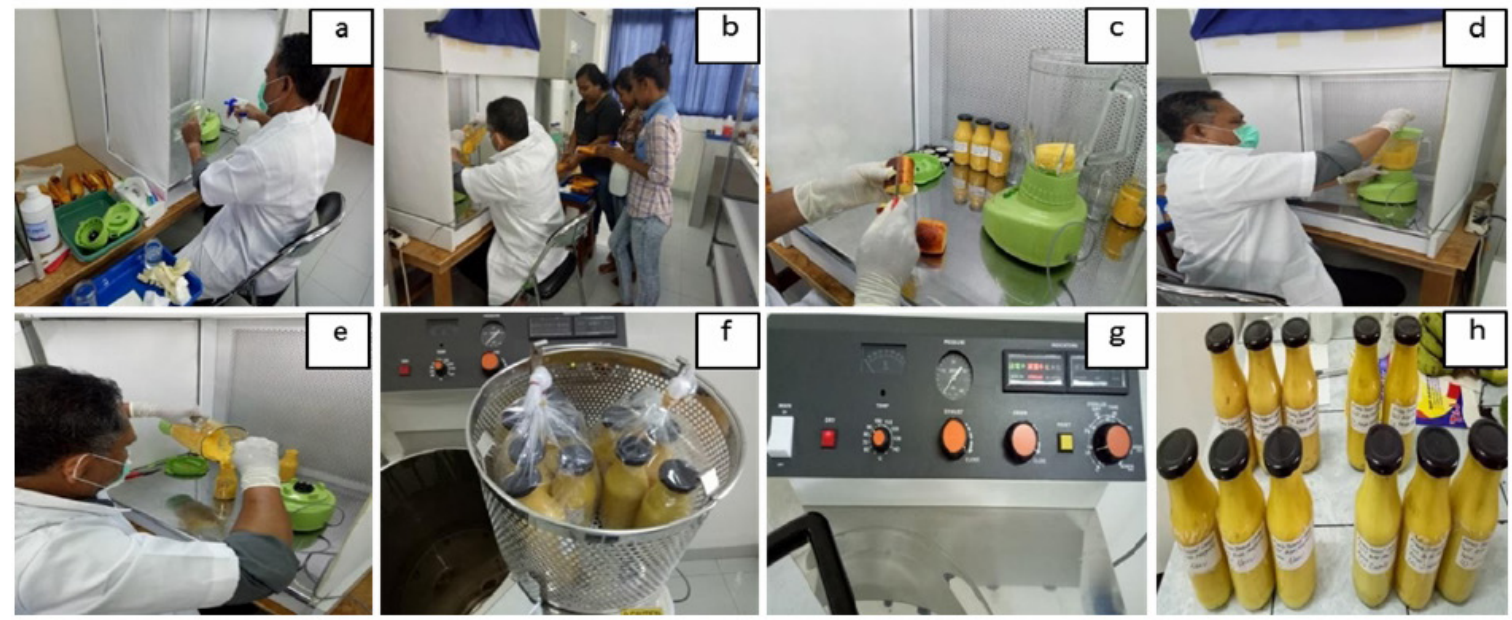

Figure 4:

(a - e) Puree preparation by blending banana fingers under the laminar flow hood, and

$(\mathbf{f}-\mathbf{h})$ Pasteurization of the product in $900 \mathrm{C}$ for $10 \mathrm{~min}$.

Quarantine Inspection: Quarantine examination is necessary for a save movement of biological materials in and outside of Maluku. The inspections are conducted thoroughly and intensively by three officials and find no necessary reasons to prevent the transport of banana materials to the Netherlands. A phytosanitary certificate is issued immediately (Figure 4). The fast respond of quarantine office, which is supported by provision of necessary documents and information by the sender institution, enable a possible rapid shipment of the materials to the address. It is also due to the fact that the puree of the skyhold-banana has been prepared and sealed in an aseptic (sterilized) condition (in the bottles), which therefore, prevent development any pest and diseases. Some fingers of needle banana, which included in the package, are removed from the hand since they become too ripen and assume to be prone for fruit fly development. The hands of needle banana are later removed entirely from the package because of the transport delay causing over-ripening of the banana fruits (Figure 5).

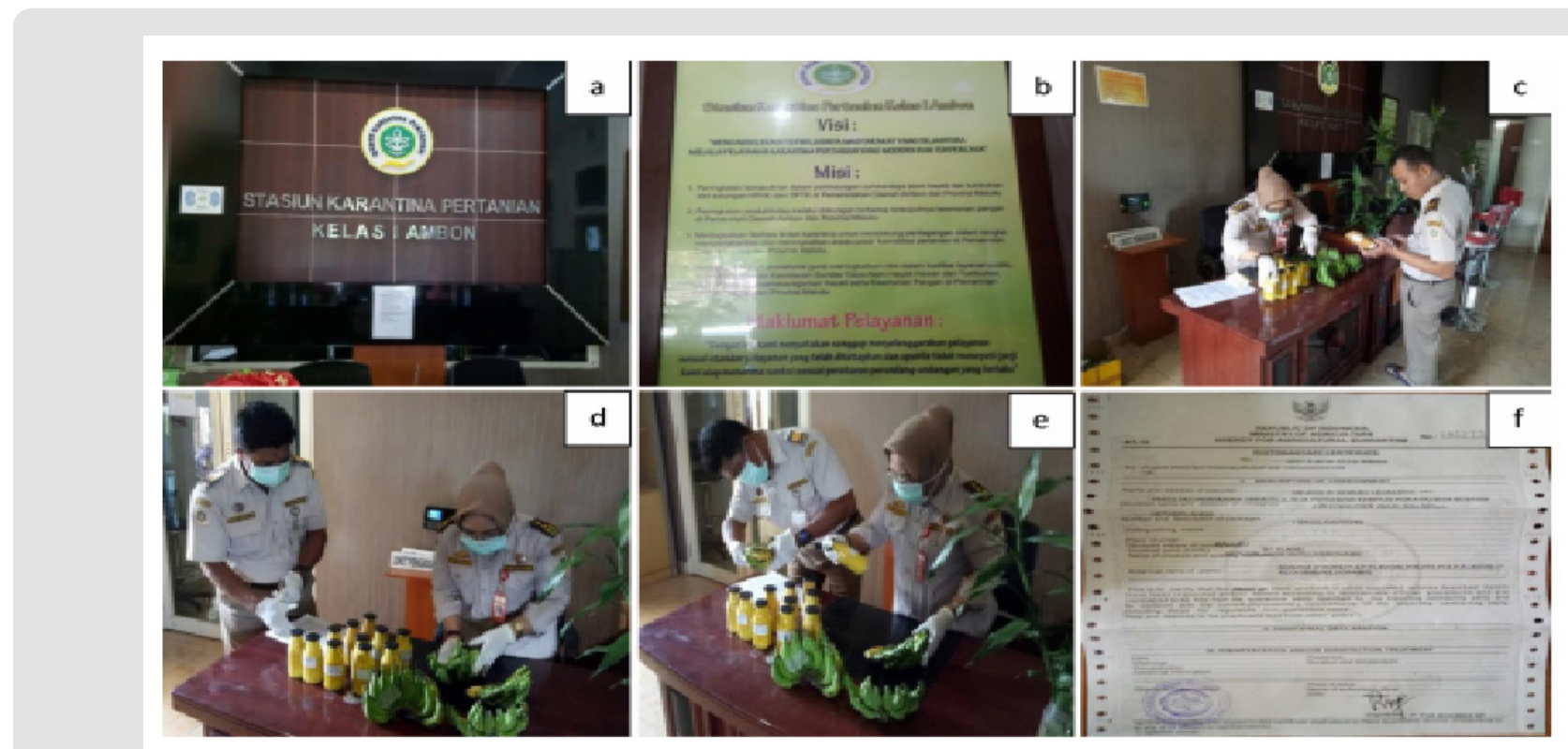

Figure 5:

(a - e) Quarantine inspection of the materials to be transferred,

(f) Prior to issuing Phytosanitary certificate.

\section{Shipment}

Several alternatives of materials shipment are available in Ambon city, including postal sending, DHL shipping company, and air-cargo. There are, however, challenges in using these shipment institutions, which were inability to guaranty the safety of fragile package, relatively long shipment period, and the need for certain additional documents to be prepared. The shipment is, therefore, done by means of personal cabin carry, with additional cost for one 
personal to carry the package to the address, Agrofair Company, Barrendrecht. Netherlands.

\section{Arrival and Description of the Materials}

The period between package preparation at the provider institution, and the arrival at the recipient institution is about 20 days. General condition of the bio-prospecting materials on the time of arrival is as follows (Van der Wall, 2017: personal communication). A part of the puree needed to be discarded due to fermentation. The rest were kept in cold temperature for further analysis. The puree is lacking the attraction due to the color, it did not show a bright orange color needed by consumers, and that might have come from an unripe banana. The powder is also seemed to be unripe, lacking the strong taste and, therefore, consumer attraction. It is, however, very nice, free-flowing powder, certainly full of fiber, minerals, vitamins, which can potentially use as fortifying agent in smoothies and cereal products. The receiving company also indicate the need to find out further on some interesting production process such as conversion rate (from raw material to powder), cost of preparation and production method.

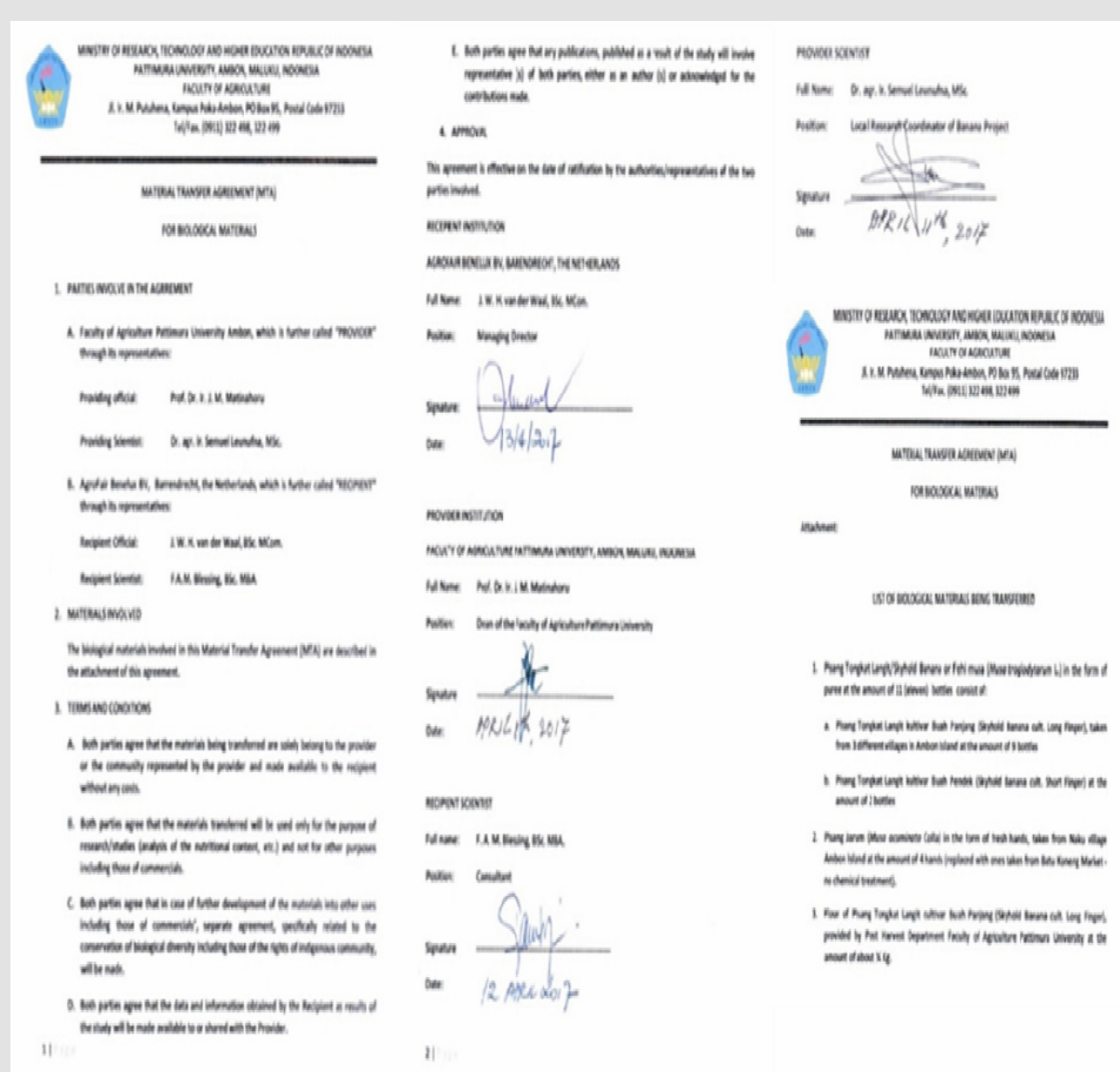

Figure 6: Material Transfer Agreement (MTA) indicating the parties involved and their signatures, terms to be abided and the list of materials transferred.

They are also very keen to have the sky-hold banana included in the ITC for Bananas in Leuven, Belgium (see [10]). MTA is issued by the provider institute, Faculty of Agriculture Pattimura University, representing indigenous community where the bio-prospecting materials are obtained (Figure 6). The MTA comprised several parts; the parties involved in the agreement and their signatures, terms to be met, accompany by an attachment of description of the materials transferred. The protection of the rights of indigenous community is clearly indicates in the terms to be abide, which mentione that (clause B) the materials transferred are only intended for research purposes and not for other purposes, and that (clause C) separate agreement will be made, in case of further commercial development of the materials, taking into account the rights of indigenous community. In addition to the above clauses, clause (A) emphasizes the party sovereign over the materials (the owner) and that the transfer is done without any cost, aside of the technical cost of preparing the materials, and clause (D) emphasizes the sharing of data obtained in the research with the provider institution.

\section{Discussion}

Convention on Biological Diversity, Rio de Janeiro, 1992 recognize the sovereignty of nations to the biodiversity components grow and develop in the country (Article 3: Principle), the necessity of fair and equitable benefit sharing arise from the 
utilization of biodiversity (Article 1: Objectives, and Article 15: Access to Genetic Resources) as well as indigenous communities' knowledge and practices related to conservation of biodiversity (Article 8: In-situ conservation) [11]. Costa Rica has been the model of countries in the world dealing with bioprospecting [12]. Since the first benefit sharing agreement made between Merk \& Co. pharmaceutical corporation of the USA and the INBio (the Instituto Nacional de Biodiversidad) of Costa Rica, in 1991 to 1999, in which the INBio provided the Merk and Co. with chemicals extracted from wild plants, insects and microorganisms, and the Merk and Co., in reciprocal, provided the INBio with more than one million \$US research funds, there have been more than 20 collaboration agreements conducted with various institutions in the world up to the year $2002[12,13]$

The benefits derived from the agreements in terms of financial include totally funded local research budget, technological transfer and infrastructure, up-front payments for conservation, strengthening of research capacity of local scientific institutions, milestone and royalty payments with MINAE (Costa Rican Ministry of Environment and Energy), while that for non- monetary benefits include training of human resources, empowerment of human resources, technology transfer, shared research results and information, negotiations expertise developed, marked information and improvement of local legislation on conservation $[12,13]$. The bio prospecting agreement and implementation indicated above has been criticized as another form of bio-piracy due to the facts that the benefits are not shared with indigenous community.

It is indicated [12], however, that the lands, in Costa Rica, where the bio-prospecting activities are conducted have no inhabitants, local farmers or indigenous community and therefore, the agreement is not involving such communities. In case of Sky-hold banana, in this study, the species has been cultivated by local indigenous farmers for generations and they have, therefore, conserve its genetic resources, and along the way have accumulated knowledge and practices in terms of suitable growing environment, cultural technology, utilizations technology as food, medicine etc. This local farmers or indigenous communities are therefore deserved to be covered in benefit agreement, should it be formulated. A study [9] find that $\beta$-carotene content in the fruit of sky-hold banana (Musa troglodytarum L.) is as high as $10 \mathrm{mg} / \mathrm{kg}$, which increase with the methods of processing (grilling or steaming) and duration of processing (5, 10 or 15 minutes) the fruits, up to $15 \mathrm{mg} / \mathrm{kg}$. A lot of studies, however, still need to be done; especially in the area of agronomy and post-harvest of the banana before further commercial development can be made possible.

For example, with the evaluation that the materials received indicate the fruit are harvested at the un-ripen stage of maturity, necessitate the studies to determine the precise harvest time. On the other hand, the preliminary evaluation of nutritional content and possible formulation in different products, provide a promising future development of sky hold banana. The proposal to include the sky-hold banana into the collection of ITC should be taken into consideration and be followed up in the future by the provider institution. ITC collected materials, which are free of viruses and preserved in the in-vitro and cryopreservation conditions, can be exchange (in case of in-vitro collection) with different research institutions for further studies or other interested parties, as well as a safety duplication of germplasm, should the germplasm at the original growing areas become threatened to erode. The ITC materials collected before the year 1993 where the CBD agreement come into force are distributed under the terms and conditions of a SMTA of the Multilateral System of Access and Benefit Sharing of the International Treaty on Plant Genetic Resources for Food and Agriculture [10]. In case of Sky-hold banana, which may be included in the collection after the CBD agreement come into force, the sovereignty rights to access and benefit sharing, belong to the people where the materials are originally obtained.

With the outbreak of diseases in the world recently; for example, that with coronavirus disease (COVID-19) [14], the role of quarantine office become highly important. It is, therefore, necessary that the quarantine inspection be part of the procedure in bio prospecting of biodiversity components in Maluku Islands, as we know from experience that some of bio-prospecting activities take place without involving proper procedures. The quick response in examining the materials and issuing of phytosanitary certificate by the quarantine office is necessary to speed up the transfer of biological materials including that of horticultural products, in this case, which are relatively easy to deteriorate. The delay in the arrival of transferred materials at the receiver institute indicates above is due to the fact that the shipping institutions have not been able to meet the demand of quick handling and shipping of the package with a guaranty of safety and less complicated procedures. With an improvement in this area of infrastructure in Maluku Province, bioprospecting activities in the Islands can be improved.

A number (about 10) of typical formulation of MTA has been described [15], each with the rights and obligations of parties involved. The MTA formulated in the present study is closely related to the one indicated as "the use permitted for the research purpose only" with additional rights and obligations. The materials transferred are intended for academic purposes which are strictly to conduct research or analysis on the banana materials. In case of further development into commercial purposes possibly attained, however, an obligation to negotiate separate agreement in which benefit sharing is taken into consideration, is necessary. The acknowledgement of the contributors in the academic context such as in the publications is also part of the MTA [15], which has been taken into account in the present publication. In addition, acknowledgement of the ownership (origin) of the biodiversity components (genetic materials) are also part of the implications of the agreement. 


\section{Conclusion}

This study presents the first and successful bio-prospecting activity between the Faculty of Agriculture Pattimura University, Indonesia and Agrofair Company Barrendrecht the Netherlands. The technical procedure implements for sky-hold banana comprises field and laboratory procedures, packaging, quarantine inspection, shipping, and signing of MTA document. Improvements need to be made in certain areas including agronomic aspect such as determining the right maturity stage prior to harvest and shipping infra-structures in Ambon city.

\section{Acknowledgement}

Mr. Hans-Willem van der Waal, Managing Director of Agrofair Company, Barendrecht the Netherlands for funding provided for technical execution of te study, Mr. Frits Blessing, senior consultant to PT Ollop, Hila Kaitetu Ambon and Mr. Fahmy Olong of PT Ollop, Hila Kaitetu Ambon Island for organizing and assisting the activity, Mr. Luud Clercx, Senior Advisor, Agrofair Company and the BLVC Project Manager for the support on paper publication.

\section{References}

1. Oyemitan IA (2017) African Medicinal Spices of Genus Piper In: Victor Kuete (Eds.)., Medicinal and Vegetables from Africa. Elsevier Inc pp. 581597.

2. Sandhu HS (2014) Bioprospecting: Pros and Cos.

3. WHO (2018) Trips, CBD and Traditional Medicines: Concepts and Questions? Report of an ASEAN Workshop on the TRIPS Agreement and Traditional Medicines, Jakarta, February 2001. p. 88.

4. Hermanto C, Edison HS, Nasution F, Riska, Malia E, et al. (2012) Triangle Banana Exploration Report, North Sulawesi and North Maluku, Indonesia. p. 1-19.

ISSN: 2574-1241

DOI: $10.26717 /$ BJSTR.2020.26.004327

Semuel Leunufna. Biomed J Sci \& Tech Res

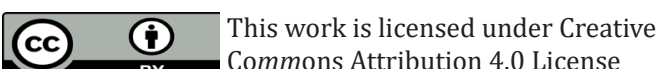

Submission Link: https://biomedres.us/submit-manuscript.php
5. Hermanto C, Sutanto A, Edison HS, Riska, Alfons, et al. (2013) Triangle Banana exploration report, Central Maluku and Lesser Sunda Islands, Indonesia. p. 1-15.

6. Sutanto A, Edison HS, Riska, Alfons, Daniells Jeff (2018) Central Maluku Banana Varieties -A Work in Progress. Available from file://C: Users/ Ivwighren/Downloads/IN140113.pdf.

7. Leunufna S, Woltering E, Hogeveen Van Echteld E, Van Der Waal HW (2018) Inventory of banana (Musa spp.) as trading commodities in Maluku Islands, Indonesia. African Journal of Agricultural Research (AJAR) 14 (33): 1693-1712.

8. Hiariej A, Karuwal RL (2015) Profil Lingkungan Tumbuh Pisang Tongkat Langit (Musa troglodytarum L.) di Kabupaten Maluku Tengah. BioWallacea Jurnal Ilmiah Ilmu Biologi 1(1): 59-63.

9. Leiwakabessy F (2018) The Effect of Method and Ripening duration on the content of beta carotene of Fe'i banana (Musa troglodytarum L.). International Journal of Applied biology 2(1).

10. (2019) International Transit Centre (ITC). ProMusa, mobilizing banana science for sustainable livelihoods.

11. UNITED NATIONS (1992) Convention on biological diversity.

12. Gamez R (2003) The link between biodiversity and sustainable development: lessons learned from Ibio's bioprospecting program in Costa Rica. p. 1-15.

13. Tamayo G, Guevara A, Gamez R (2004) Microbial Diversity and Bioprospecting. Edited by Alan T Bull. Washington (DC): ASM Press. $\$ 129.95$. xix + 496 p + 11 pl; ill.; subject index. The Quarterly Review of Biology 79(3): 309-310.

14. World Health Organization (WHO) (2020) Coronavirus Disease (COVI19) Outbreak.

15. Barton John H, Wolfang E Siebeck (1994) Material Transfer Agreement in Genetic resources exchange - The case of the international Agricultural Research Centers. Issues in Genetic Resources No. 1, International Plant Genetic Resources Institute, USA.

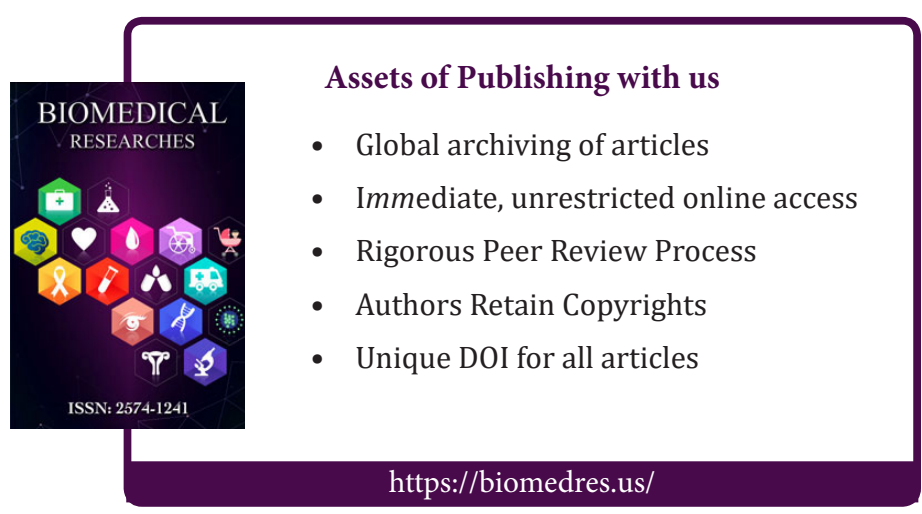

